When nitrous oxide was substituted $\mathrm{PaCO}_{2}$ rose from 44.6 to $50.5 \mathrm{~mm} \mathrm{Hg}$. This difference is statistically significant $(P<0.01)$. Full details of the blood gas changes are shown in the Table.

\section{Discussion}

Cardiac arrhythmias are a common occurrence during laparoscopy, especially when carbon dioxide is used to inflate the peritoneal cavity. These arrhythmias are almost certainly related to the high $\mathrm{PaCO}_{2}$ in conjunction with the use of halothane, but they may occasionally be due to reflex activity from the distending abdomen. They are sometimes seen when the $\mathrm{PaCO}_{2}$ is relatively low. There is little evidence, however, that these arrhythmias are harmful to the patient. The fear that they may progress to ventricular fibrillation or cardiac arrest would seem groundless in view of the large number of these operations which have been carried out (more than 4,000 in this area) without incident. We are aware that cases of cardiac arrest have occurred (Scott, 1970) but it would seem that these are due to carbon dioxide embolus resulting from accidental insertion of the Verrés needle into the pregnant uterus, no pressure-limiting device having been used during insufflation.

The arrhythmias most commonly seen in this series were fusion beats occurring after the $P$ waves and causing bigeminy. This arrhythmia is often impossible to diagnose by palpation of the radial pulse as the extrasystoles occur only fractionally before the expected normally conducted beat. Little or no haemodynamic disadvantage is likely to accrue from this arrhythmia. Alexander (1971) described "nodal" arrhythmias during oral surgery which may be identical with those observed by us, but we would not consider them to be supraventricular.
Carbon dioxide has been chosen as the gas for peritoneal insufflation because of its high solubility. This ensures the rapid absorption of any remaining gas postoperatively and gives a degree of safety if, by mischance, the gas is injected intravascularly. However, nitrous oxide has advantages over carbon dioxide for this purpose. Cardiac arrhythmias are much less frequent and the respiratory drive is less pronounced owing to the lower $\mathrm{PaCO}_{2}$ that is produced. Our results indicate that the major cause of a rise in $\mathrm{PaCO}_{2}$ when carbon dioxide is used is due to absorption from the peritoneal surface. The splinting of the diaphragm which undoubtedly occurs is responsible for about 25 to $30 \%$ of the rise and, of course, still occurs if nitrous oxide is used. Nitrous oxide has a high solubility in plasma $(68 \%$ of that of carbon dioxide) and the residual gas left in the abdomen will disappear quickly. It does support combustion, but as there is no question of the diathermy setting fire to the abdominal contents this is of no importance. Reduced respiratory drive compared with that seen with carbon dioxide gives a quieter field for the surgeon. Several hundred laparoscopies have now been carried out with nitrous oxide in this way without untoward incidents.

We wish to thank Professor R. J. Kellar for allowing us to study his patients. Miss E. McLachlan, Mr. A. McKinnon, and Mr. T. McFetters gave invaluable technical help. We are especially grateful to Dr. H. L. Marriott, St. Petersburg, Florida, U.S.A., and Professor Schamroth, Witwatersrand University, South Africa, for their valued opinions regarding the E.C.G. tracings.

\section{References}

Alexander, J. P. (1971). British fournal of Anaesthesia, 43, 773. Scott, D. B. (1970). Anaesthesia, 25, 590.

\title{
Role of Venous Needle Hub in Extracorporeal Pressure Changes during Haemodialysis
}

University Department of Medicine and Artificial Kidney Unit, Maryfield Hospital, Dundee DD4 7TL

W. K. STEWART, M.B., CH.B., F.R.C.P., Senior Lecturer in Medicine M. A. MANUEL, M.B., CH.B., F.C.P.(S.A.), Medical Registrar LAURA W. FLEMING, B.SC., Research Assistant increases inadvertently promote ultrafiltration and can result in the uncontrolled removal of extracellular fluid. Our findings suggest that the properties of the venous needle hub may significantly influence the incidence of pressure increases.

\section{Method}

Five 14 gauge needle assemblies were tested (Fig. 1). The first (alloy) was the Bardic needle (No. 1614 EPS-alloy) with an aluminium alloy hub. The second (alloy-modified) was basically the first needle altered locally so as to create a smooth internal incline at the hub. The third (plastic hub) was the Bardic plastic hub needle (No. 1614 EPS-plastic). The fourth (fistula set) was the Travenol arteriovenous fistula set (No. AKM0276), which has a shaft set into a plastic (nylon) hub attached to plastic tubing (approximately $34 \mathrm{~cm}$ long and $2.8 \mathrm{~mm}$ internal diameter). The thin-walled stainless steel shafts of the needles were all siliconized. The fifth assembly (cannula) was the 14 gauge Argyle Medicut, which has an extruded polypropylene cannula with partly siliconized, smoothly-curving luminal contours between tip and base, there being no sharply demarcated hub. Although all five needle assemblies were nominally 14 gauge, indicating that the external diameters of the shafts 


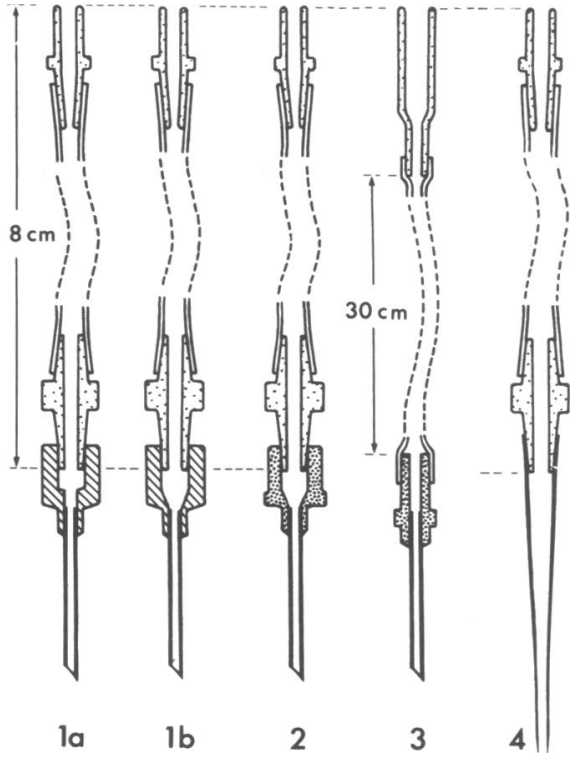

FIG. 1-Types of needle assemblies tested: 1a, alloy; 1b, alloy-modified 2, plastic hub; 3, fistula set; 4, cannula. Except for 3, each is shown with the extension tube attached.

were between 2.00 and $2.12 \mathrm{~mm}$ (British Standard 3387:1962), the haemodynamically important internal diameters vary more (Table I).

The trial needle assemblies were used in the return vein only. The plastic hub needle was used throughout the trial for the arterial end. Except for the fistula set, the needles and the cannula were all connected to the blood return (venous) line by an $8-\mathrm{cm}$ length of plastic extension tubing (Stewart et al., 1969).

TABLE I-Incidence of Increases in Venous Pressure

\begin{tabular}{|c|c|c|c|c|c|c|}
\hline \multirow{2}{*}{$\begin{array}{l}14 \text { Gauge } \\
\text { Needle } \\
\text { Assembly }\end{array}$} & \multicolumn{2}{|c|}{ Shaft Diameter* } & \multirow{2}{*}{$\begin{array}{c}\text { Shaft } \\
\text { Length } \S \\
(\mathrm{mm})\end{array}$} & \multirow{2}{*}{$\begin{array}{l}\text { No. of } \\
\text { Dialyses } \\
\text { Assessed }\end{array}$} & \multicolumn{2}{|c|}{$\begin{array}{l}\text { Increased } \\
\text { Pressure }\end{array}$} \\
\hline & $\underset{(\mathrm{mm})}{\text { External }}$ & $\underset{(\mathrm{mm})}{\text { Internal }}$ & & & No. & $\%$ \\
\hline $\begin{array}{l}\text { Plastic hub } \\
\text { Cannula }\end{array}$ & $\begin{array}{l}2 \cdot 10 \\
2 \cdot 10 \dagger\end{array}$ & $\begin{array}{l}1.83 \\
1.65 t\end{array}$ & $\begin{array}{l}37 \cdot 5 \\
67 \cdot 5\end{array}$ & $\begin{array}{l}50 \\
25\end{array}$ & $\begin{array}{l}2 \\
3\end{array}$ & $\begin{array}{r}4.0 \\
12 \cdot 0\end{array}$ \\
\hline $\begin{array}{l}\text { Alloy .. } \\
\text { Alloy-modified } \\
\text { Fistula set } \quad \text {.. }\end{array}$ & $\begin{array}{l}2 \cdot 10 \\
2 \cdot 10 \\
2 \cdot 00\end{array}$ & $\begin{array}{l}1.83 \\
1.83 \\
1.55\end{array}$ & $\begin{array}{l}37.5 \\
37.5 \\
39 \cdot 0\end{array}$ & $\begin{array}{l}25 \\
25 \\
25\end{array}$ & $\begin{array}{l}16 \\
14 \\
15\end{array}$ & $\begin{array}{l}64 \cdot 0 \\
56 \cdot 0 \\
60 \cdot 0\end{array}$ \\
\hline
\end{tabular}

* Supplied by manufacturer on request.

† Measured $15 \mathrm{~mm}$ proximal to tip.

Measured at tip (minimum internal diameter).

$\S$ Measured from end of metal within hub to near-end of bevel at tip.

The five patients studied had Brescia-Cimino fistulae and all were dialysed in two sessions for a total of 16-24 hours per week. Ten plastic hub needles and five of each of the other varieties were allocated to each patient in a predetermined but random order.

The dialysis system consisted of a monitored pump dialysate supply (Dylade Model B Series 2) with disposable coil units (Travenol Ultra-flo 100) enclosed in a steel container (Wakefield et al., 1970).

Heparin (mucous B.P.g) $(25,000$ units in $500 \mathrm{ml}$ of $5 \%$ w/v dextrose in water) was infused continuously into the arterial line at a rate of about $25 \mathrm{ml}$ per hour. Half-hourly clotting times, on samples taken proximal to the point of heparin infusion, were maintained between 20 and 45 minutes.

The "venous pressure" gauge of the Dylade pump-monitor was used to record pressures hourly from the air-bubble trap. The blood pump rate was fixed at $180 \mathrm{ml}$ per minute. An increase in venous pressure was defined as a rise exceeding $50 \%$ of the initial pressure for that dialysis. Whenever venous pressures in excess of $100 \mathrm{mg} \mathrm{Hg}$ were observed the needle was repositioned in the vein. If this failed to reduce the pressure the needle was irrigated with heparinized saline. If both manoeuvres failed the venous pressure was reduced by decreasing the blood pump rate. As a last resort the needle assembly was replaced with the plastic hub type which never required changing because of high pressures. Dialyses in which the needle was changed, or which resulted in a burst coil, were excluded from the trial and repeated.

\section{Results}

Incidence of Venous Pressure Increases (Table I).--Use of the plastic hub needle and the cannula was associated with a $4 \%$ and $12 \%$ incidence of increases respectively, compared with a $56 \%$ to $64 \%$ incidence for the other needles ( $P<0.001)$. There was some individual patient variation with the incidence of increases per patient ranging from a minimum of $17 \%$ to a maximum of $43 \%$ irrespective of the needle assembly used ( $P<0.05$ for the maximum difference).

Mean Venous Pressures during Dialysis (Table II).-The mean of the initial venous pressure on beginning dialysis was significantly higher with the fistula set $(68 \mathrm{~mm} \mathrm{Hg})$ than with the other needle assemblies (47 to $49 \mathrm{~mm} \mathrm{Hg})(\mathbf{P}<0.001)$. A

TABle II-Mean Venous Pressure $(\mathrm{mm} \mathrm{Hg}) \pm S . D$.

\begin{tabular}{|c|c|c|c|c|}
\hline \multicolumn{3}{|c|}{ Needle Assembly } & Initial (after Connexion) & Maximum \\
\hline $\begin{array}{ll}\text { Plastic hub } & \ldots \\
\text { Cannula } & \ldots\end{array}$ & $\therefore$ & $\begin{array}{l}\ldots \\
\cdots\end{array}$ & $\begin{array}{l}48 \pm 11 \\
47 \pm 15\end{array}$ & $\begin{array}{l}54 \pm 14 \\
62 \pm 24\end{array}$ \\
\hline $\begin{array}{l}\text { Alloy .. } \\
\text { Alloy-modified } \\
\text { Fistula set } \quad .\end{array}$ & $\begin{array}{l}. \\
\cdots\end{array}$ & $\begin{array}{l}\ldots \\
\cdots\end{array}$ & $\begin{array}{l}49 \pm 10 \\
47 \pm 10 \\
68 \pm 17\end{array}$ & $\begin{array}{r}108 \pm 43 \\
93 \pm 38 \\
114 \pm 41\end{array}$ \\
\hline
\end{tabular}

comparison of the mean maximum pressures recorded for each type of needle assembly showed that the value for the plastic hub needle was significantly lower $(P<0.001)$ than the value for the alloy needles or the fistula set, and it was also probably significantly lower than for the cannula $(P<0.05)$. Differences in the maximum pressures recorded with the alloy needles and fistula set were not significant. Modification of the alloy hub made no difference either to the incidence of pressure increases or to the mean venous pressure levels at the onset of, or during, dialysis.

Blood Clot Formation.-We failed to establish a definite correlation between demonstrable clots, found on reaming-out the needle hub immediately after dialysis, and the higher venous pressures. Clots were found at only $7(13 \%)$ out of 54 examinations of the needle hubs. In six of the seven instances high venous pressures had been recorded. On 47 (87\%) occasions the needle was "clear," despite a $36 \%$ incidence of recorded venous pressure increases.

\section{Discussion}

Nidus et al. (1971) showed the haemodynamic importance of the internal diameter and length of the needles and the tubing of fistula sets. The higher initial venous pressure found with the fistula set reflects influences on blood flow before any thrombus formation has taken place, and could be explained by the comparatively narrower bore and longer shaft of the needle, the narrower and longer plastic tube or the haemodynamic characteristics of the hub, or a combination of these. The data do not permit particularization.

The progressive increases in pressure often noted during dialysis are probably the result of platelet thrombus formation. Blood platelets are known to play a key part in the beginning of thrombus formation in areas of high-velocity blood flow (Jørgensen et al., 1967; Mustard and Packham, 1970). Adequate 
heparinization does not ensure that platelet thrombi cannot form. Heparin (like the coumarins) actively prevents fibrin deposition but does not lessen platelet adhesion and transformation (Sherry, 1971). Although it was not always possible to demonstrate thrombus deposition in the needle when the venous pressures were high, it is possible that clots become dislodged both during dialysis and also when coil blood is returned at the end of dialysis. The contribution made by the actual material of the needle hubs to the net local thrombogenic effect is unpredictable (Scarborough, 1971). Nylon can be markedly thrombogenic (Williams, 1971) but any such effect may be obviated by silicone.

Local rheological characteristics at the hub are likely to have a pronounced effect on thrombogenesis (Brinkhous, 1969). Sudden changes in luminal diameter are likely to bring about boundary layer separation in the blood stream with the formation of a stagnation point (Fox and Hugh, 1966; Leith et al., 1969) and its attendant liability to thrombus formation (Petschek et al., 1967). Both the hub of the plastic hub needle and the cannula have siliconized smooth internal contours, which would be expected to reduce turbulent flow (Whitmore, 1968) and also platelet adhesion of fibrin deposition (Jaques et al., 1946; Perkins et al., 1960). Both the needle of the fistula set and the unmodified alloy needle have haemodynamically disadvantageous projecting edges set in the blood flow path. These would predispose to turbulent flow and thrombus formation irrespective of the material used. Since the modified alloy needle was no better in use than the unmodified one, it would seem that the metal material of the hub could be clot-promoting, thus outweighing the improved flow path, but the surface finish after milling-out was admittedly imperfect.

In general, we conclude that thrombi are the main factor in the production of high venous pressures developing during dialysis, but there are obviously several factors affecting the extent of clot formation. Variation between patients may reflect individual differences in platelet adhesiveness.

This conclusion-platelet thrombus formation, despite heparinization, occurring at the venous end of an extracorporeal arteriovenous shunt-is similar to that described by Shionoya (1927) when working with collodion tubes in rabbits. The internal configuration of the hub of the venous return needle is critical in this context.

Our thanks are due to the staff of the artificial kidney unit for their conscientious participation.

\section{References}

Brinkhous, K. M. (1969). In Thrombosis, ed. S. Sherry, K. M. Brinkhous, E. Genton, and J. M. Stengle, p. 547. Washington, D.C., National Academy of Sciences.

British Standards Institution (1962). British Standard 3387. London, B.S.I.

British Standards Institution (1962). British Standard 3387. Lond
Fox, J. A., and Hugh, A. E. (1966). British Heart fournal, 28, 388.

Jaques, L. B., Fidlar, E., Feldsted, E. T., and Macdonald, A. G. (1946). Canadian Medical Association fournal, 55, 26.

Jorgensen, L., Rowsell, H. C., Hovig, T., and Mustard, J. F. (1967). American Fournal of Pathology, 51, 681.

Leith, W. C., et al. (1969). Transactions. American Society for Artificial Internal Organs, 15, 272.

Mustard, J. F., and Packham, M. A. (1970). Circulation, 42, 1.

Nidus, B. D., Matalon, R., Deutsch, P., and Eisinger, R. P. (1971). Nephron, 8,191

Perkins, H. A., Osborn, J. J., and Gerbode, F. (1960). Fournal of Cardiovascular Surgery, 1, 180.

Petschek, H. E., Kantrowitz, A. R., and Adamis, D. (1967). Proceedings of the Annual Conference on Engineering in Medicine and Biology, 9, 19.6.

Scarborough, D. E. (1971). Current Topics in Pathology, 54, 95.

Sherry, S. (1971). New England fournal of Medicine, 284, 1324.

Shionoya, T. (1927). Fournal of Experimental Medicine, 46, 19.

Stewart, W. K., Goddard, J. D., and Wakefield, W. C. (1969). British Medical fournal, 1, 644 .

Wakefield, W. C., Goddard, J. D., and Stewart, W. K. (1970). Bio-Medical Engineering, 5, 330.

Whitmore, R. L. (1968). Rheology of Circulation, p. 155. Oxford, Pergamon Press.

Williams, D. F. (1971). Bio-Medical Engineering, 6, 205.

\title{
Acute Renal Failure and Open Heart Surgery
}

\author{
E. D. YEBOAH, AVIVA PETRIE, J. L. PEAD
}

British Medical fournal, 1972, 1, 415-418

\section{Summary}

A retrospective study of 428 open heart operations showed the incidence of mild and severe renal failure to be $26 \%$ and $4.7 \%$ respectively. The mortality rate was $38 \%$ in the mild cases and $70 \%$ in the severe cases. Only half of the patients whose death was associated with renal failure showed macroscopic or microscopic renal lesions at necropsy. The patients who developed renal impairment had significantly higher mean preoperative blood urea (40 $\mathrm{mg} / 100 \mathrm{ml}$ ) than the non-renal-failure cases (33 mg/100 ml). Periods of perfusion over 60 minutes, mean perfusion pressures below $80 \mathrm{~mm} \mathrm{Hg}$, and multiple valve replacement operations also increased the incidence of renal failure. There was no statistical correlation

Hammersmith Hospital, London W12 OHS

E. D. YEBOAH, M.B., B.CHIR., F.R.C.S., Formerly Registrar in Cardiac Surgery and now Registrar in Urology

J. L. PEAD, M.B., B.S., M.R.C.PATH., Senior Registrar, Department of Morbid Anatomy

Royal Postgraduate Medical School, London W12 OHS

AVIVA PETRIE, M.sc., Honorary Lecturer in Medical Statistics between the age of individual patients, the degree of cooling, and postoperative blood urea values. There was no evidence to suggest that frusemide or mannitol separately or together influenced the development of renal failure. Peritoneal dialysis was preferred for initial treatment of patients with severe renal failure, and haemodialysis was required only in special cases.

\section{Introduction}

Acute renal failure is a serious complication of operations which involve total body perfusion, but the reported incidence of the complication has varied widely between 2.0 and $13.5 \%$ (Rand et al., 1963; Sawyer et al., 1963; Norman et al., 1964; Yeh et al., 1964; Kulatilake and Shackman, 1965; Porter et al., 1966, 1967).

The present report is based on a retrospective study of 428 open heart operations with total body perfusion carried out on 267 male and 161 female patients aged 5 to 65 years during the period January 1968 to June 1970 (Table I).

The Melrose rotating disc oxygenator was used in 317 cases and Temptrol or Rygg bag bubble oxygenators in 111. The oxygenators were primed with a mixture of $1,500 \mathrm{ml}$ of whole blood (acid citrate dextrose), $500 \mathrm{ml}$ of Hartmann's solution, and $1,000 \mathrm{ml}$ of $5 \%$ dextrose; sodium bicarbonate $60 \mathrm{mEq}$ was added whenever the body surface exceeded $1.3 \mathrm{~m}^{2}$. Flow rates 